\title{
CONSIDERAC̣ÕES SOBRE A IDADE DO GRUPO BAMBUÍ COM BASE EM ANÁLISES ISOTÓPICAS DE Sr E Pb
}

\author{
J. G. PARENTI COUTO*, U. G. CORDANI**, K. KAWASHITA**, S. S. Iyer*** e N. M. P. MORAES***
}

\begin{abstract}
Based on radiometric ages, the Bambui Group deposition time is related to the end of the Precambrian. However, the ages determined and released through scientific magazines are not in agreement (600-1 350 m.y.) and many doubts about the geochrological picture of this important lithostratigraphic unit remained for a long time. As a result of the work developed by Metamig, CPGeo (IG-USP) and IPEN (SP), $\mathrm{Rb} / \mathrm{Sr}$ and $\mathrm{Pb} / \mathrm{Pb}$ isotopic determinations were done on 31 rocks samples and 17 galenas collected from the Bambuí Basin distributed in Minas Gerais State. The $\mathrm{Rb} / \mathrm{Sr}$ ages of 590 m.y. for Pirapora Formation, 620 m.y. for Três Marias Formation, and 640 m.y. for the Paraopeba Formation situated in the stable àrea are linked to sedimentation processes. In the Paracatu region the age of $680 \mathrm{~m} . \mathrm{y}$. found for the Paraopeba Formation is related to metamorphic events. The lead isotopic ratios from the galenas suggest an isotopic evolution in two stages. The first ended with the lead separation from the mantle and its incorporation to the crust during events of the Transamazonic Cycle. The second ended when the lead were incorporated to the galenas and seems to be related to one or more events of the Brazilian Cycle.
\end{abstract}

INTRODUÇÃO O Grupo Bambuí ocupa uma posição de destaque na geologia do Estado de Minas Gerais, não só devido a sua distribuição areal, quase um terço da superfície do Estado, como também por conter importantes recursos minerais em exploração, como zinco, chumbo, fosfato, além de ardósias, fluorita e, em destaque, calcáreos e dolomitos. Diante desse grande potencial, tem sido alvo permanente de pesquisa por parte de inúmeras empresas de mineração e prospectores particulares. Idêntico interesse tem despertado da comunidade científica que a ele tem dedicado inúmeros trabalhos.

A idade do Grupo Bambuí tem sido objeto de permanente preocupação de quantos estudiosos o têm pesquisado, remontando a pouco mais de um século a primeira tentativa nesse sentido, a qual se deve a Liais que, em 1872, lhe atribuiu uma idade cretácea. Desde então inúmeros trabalhos têm abordado esse importante aspecto e, por diferentes métodos ou deduçðes, obtido idades diversas que vãō do Mesozóico ao Pré-Cambriano. A primeira tentativa de utilizar a Paleontologia na datação do Bambuí foi feita por Derby, em 1879, ao identificar certos tipos de estruturas ocorrentes nas grutas de Bom Jesus da Lapa (BA) como fósseis, atribuindo-lhes idade Siluriana. Beurlen (1956), ao reestudar tais estruturas, considerou-as de origem inorgânicas, datando o Bambuí como de idade Ordoviciana. A primazia na identificação de estruturas tidas como de origem orgânica nas rochas carbonatadas do Bambuí coube a Beurlen e Cassedane com a descoberta de collênias, em 1963. Cloud e Dardenne, em 1973, identificaram, em dolomitos da região de Vazante (MG), Conophyton aff. C. Metula Kiriechenko aos quais atribuíram idade Rifeano Médio (950-1 350 m.a., mais provável em torno de 1000 m.a.). Essa idade difere da obtida por Marchese (1974) com estromatólitos Supergrupo Gimnosolenida ocorrentes em calcários negros grafitosos da regiăo de Sete Lagoas (MG), considerados como pertencentes ao Rifeano Superior (650-950 m.a.).

Os métodos radiométricos foram introduzidos como instrumento de datação do Bambuí por Fenner que, em 1928, datou veios de pegmatitos que ocorrem a leste de Minas Gerais, obtendo uma idade mínima de 350 m.a. Inúmeras outras tentativas foram feitas utilizando essa metodologia, destacando-se as iniciativas pioneiras de Amaral (1966), ao utilizar o método $\mathrm{Pb} / \mathrm{Pb}$ em galenas; Amaral e Kawashita (1967), utilizando o método $\mathrm{Rb} / \mathrm{Sr}$ em folhelhos; e Almeida e Hassui (1969), que utilizaram o método K/Ar em filitos da Formação de Paracatu.

A época de deposição do Grupo Bambuí tem sido atribuída ao final do Pré-Cambriano, com base em dataçð̃es radiométricas (Amaral e Kawashita, 1967; Bonhomme, 1976; e Cordani et al., 1978) e também em seu conteúdo fossilífero (Cloud e Dardenne, 1973; e Marchese, 1974). Entretanto, os valores das idades referidas nos trabalhos acima indicados são discrepantes (600-1 350 m.a.), ocasionando sérias dúvidas quanto ao quadro geocronológico dessa importante unidade litoestratigráfica.

METODOLOGIA DAS ANÁLISES ISOTÓPICAS O método de datação isotópica $\mathrm{Rb} / \mathrm{Sr}$ foi utilizado diretamente sobre a rocha total. Como a dificuldade interpretativa reside principalmente na componente

\footnotetext{
* Metais de Minas Gerais S.A. - Metamig - Belo Horizonte (MG)

** IG, USP - São Paulo (SP)

*** IPEN - São Paulo (SP)
} 
detrítica, foram selecionadas amostras ou porçðes em que a granulometria era a mais fina possível, em geral siltitos e/ou folhelhos. Da mesma forma, foram evitadas amostras carbonatadas, cujo Sr presente poderia alterar totalmente os parâmetros das isócronas. Após a seleção preliminar e análise semiquantitativa de $\mathbf{R b}$ e $\mathrm{Sr}$ por fluorescência de raios $X$ foram selecionadas 31 amostras para determinaçðes isotópicas.

As determinações quantitativas de rubídio $e$ estrôncio totais foram efetuadas segundo a técnica preconizada por Reynolds (1963), com adaptaçðes descritas por Kawashita (1973). Os erros analíticos nas determinações de rubídio total e de estrôncio total, em amostras com teores da ordem de ou superiores a $50 \mathrm{ppm}$, são estimados em cerca de $2 \%$. As amostras com teores menores que $50 \mathrm{ppm}$ foram analisadas adicionalmente pelo método de diluição isotópica. Neste caso, os procedimentos e as técnicas analíticas eståo descritas pormenorizadamente em Kawashita et al. (1974). Os erros analíticos por diluição isotópica foram em geral da ordem de $10 \%$.

As galenas analisadas foram em sua totalidade extraídas manualmente da rocha utilizando-se instrumentos adequados, dependendo das dimensðes dos cristais. Algumas amostras, em que os cristais eram de dimensðes milimétricas e com impurezas incrustadas, foram desagregadas e separadas com utilização de bromofórmio. As galenas foram subseqüentemente lavadas com $\mathrm{HCl} 3 \mathrm{~N}$ e água destilada.

Para as determinações de composição isotópica do chumbo, as amostras foram dissolvidas em $\mathrm{HCl} 6,2 \mathrm{~N}$ e mais tarde purificadas por ebulição por uma coluna contendo resina aniônica AG 1x8. O esquema de separação adotado é o mesmo descrito por Strelow e Van Toerien (1966). A uma gota do eluído contendo chumbo foram adicionadas, em cada caso, uma gota de solução de sílica gel (preparação a partir de sílica gel Merck $60 \mathrm{HR}$ extrapura) e uma gota de ácido fosfórico $0,75 \mathrm{~N}$. Pequena parte dessa mistura foi depositada a seguir sobre um filamento simples de rênio previamente desgaseificado e limpo.

As análises isotópicas, tanto de $\mathrm{Sr}$ bem como de $\mathrm{Pb}$, foram obtidas utilizando-se espectrômetros de massa de fonte sólida da Varian, modelo TH-5. Na Tab. 1 constam os resultados de análises isotópicas de Sr que serviram para o controle de qualidade das medidas obtidas

Tabela 1 - Análises isotópicas em amostras-padrão

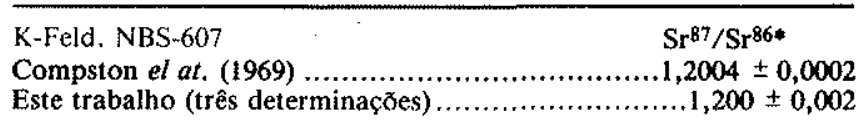

Sr $\mathrm{Co}_{3}$ Eimer e Amend

Faure et al. (1965) .......

$0,7084 \pm 0,0003$

Este trabalho (três determinaçőes).

$0,7083 \pm 0,0013$

Granito

Padrăo interno de controle:

S-10 (doze determinaçøes) ............................1,278 $\pm 0,004$

* Razðes normalizadas para $(86 / 88)=0,1194$ com o espectrômetro TH-5, do CPGeo, utilizado para análises de $\mathrm{Sr}$ do presente trabalho. Todas as razōes $\mathrm{Sr}^{87} / \mathrm{Sr}^{86}$ foram normalizadas admitindo-se para a razăo $\mathrm{Sr}^{86} / \mathrm{Sr}^{88}=0,1194 \mathrm{e}$ as idades isocrônicas foram calculadas utilizando-se o programa PISODY Kawashita (1973). $O$ valor de $\lambda$ para $R^{87}$ admitido foi de $1,42 \cdot 10^{-11}$ anos $^{-1}$. Os dados analíticos completos das determinaçסes $\mathrm{Rb}$-Sr deste trabalho aparecem na Tab. 2.

No caso específico do chumbo, as determinaçðes foram efetuadas num sistema de aquisiçăo e processamen to de dados Spectro System 160-TH acoplado ao espectrômetro de massa do IPEN.

$\mathrm{Na} \mathrm{Tab}, 3$ constam resultados de análises isotópicas da galena padrão de Broken Hill (T-1003) obtidos pela técnica descrita, juntamente com determinaçōes obtidas por outros laboratórios. Os valores ilustrados são relativos à média de cinco diferentes determinações efetuadas em diferentes ocasioes durante o transcorrer do presente trabalho. $\mathrm{O}$ desvio-padrão é da ordem de $0,2 \%$ a $0,3 \%$.

Todas as determinações isotópicas de $\mathrm{Pb}$, apresentadas na Tab. 4, foram normalizadas utilizando-se fatores adequados derivados a partir da comparação com os valores apresentados na Tab. 1. Nesta mesma tabela constam também os dados isotópicos de galenas do Grupo Bambuí publicados por Amaral (1968) e por Cassedanne e Lasserre (1969).

DISCUSSÃO DOS DADOS Rb-Sr Trinta e uma novas determinações de idade $\mathrm{Rb}$-Sr em rocha total foram efetuadas em rochas do Grupo Bambuí, de Minas Gerais, escolhidas cuidadosamente com base em amostragem muito maior realizada pela Metamig. Os objetivos principais foram os de caracterizar a idade das diferentes formaçðes, nas localidades-tipo, efetuar alguma correlação com base na distribuição geográfica dos pontos amostrados e verificar a eventual influência do tectonismo que afetou a parte ocidental da área estudada pela Metamig, já no âmbito da faixa de dobramentos Brasília. A Tab. 2 reúne os dados analíticos completos das dataçðes $\mathrm{Rb}-\mathrm{Sr}$ realizadas e a Fig. 1 apresenta a localização das amostras escolhidas. Os dados Rb-Sr foram utilizados para a construção das Figs. 2, 3 e 4, que serão comentadas e interpretadas a seguir, em termos da idade e evolução sofrida pelas rochas, em cada caso.

A Fig. 2 reúne os dados relativos a quatro amostras da Formação Pirapora (amostras AY-3, AY-4, AY-6 e AY-10) coletadas num mesmo afloramento nas proximidades de Pirapora. Trata-se de siltitos com alguns fragmentos líticos sem quaisquer evidências de tectonismo e/ou metamorfismo. Análises difratométricas indicaram a presença de ilitas e cloritas como principais minerais de argila, acompanhadas, porém, por grande quantidade de quartzo e feldspatos, revelando a importância da componente detrítica. $O$ alinhamento dos pontos analíticos no diagrama isocrônico é relativamente bom e a isócrona por eles traçada indica uma idade de $590 \pm 40$ m.a., com a razão inicial $\mathrm{Sr}^{87} / \mathrm{Sr}^{86}$ de 0,7115 . Tendo em vista as características das amostras, é provável que tenham ocorrido as condiçðes preconizadas por Cordani et al. (1978) de mistura mecânica homogênea dos componentes detríticos, na época da deposiçăo, a qual seria correspondente à idade indicada. A 
Tabela 2 - Amostras de rochas sedimentares do Grupo Bambuí. Dados analíticos $\mathrm{Rb} / \mathrm{Sr}$ em rocha total

\begin{tabular}{|c|c|c|c|c|c|}
\hline No do campo & $\begin{array}{c}\text { N. Lab. } \\
\text { (SPR) }\end{array}$ & $\begin{array}{c}\mathrm{Rb} \\
(\mathrm{ppm})\end{array}$ & $\begin{array}{c}\mathrm{Sr} \\
(\mathrm{ppm})\end{array}$ & $\mathrm{Rb}^{87} / \mathrm{Sr}^{86}$ & $\mathrm{Sr}^{87} / \mathrm{Sr}^{86}$ \\
\hline $\mathrm{AX}-2$ & 3952 & 154,4 & 63,1 & 7,13 & 0,7695 \\
\hline$A Y-3$ & 3889 & 75,3 & 66,5 & 3,27 & 0,7392 \\
\hline$A Y-4$ & 3890 & 159,6 & 57,6 & 8,05 & 0,7827 \\
\hline$A Y-6$ & 4040 & 180,6 & 44,4 & 11,81 & 0,8046 \\
\hline$A Y-10$ & 3892 & 55,5 & 87,5 & 1,84 & 0,7268 \\
\hline$B X-3$ & 3893 & 170,6 & 102,2 & 4,86 & 0,7563 \\
\hline $\mathrm{BX}-8$ & 3894 & 137,9 & 385,2 & 1,04 & 0,7221 \\
\hline BX-9 & 3895 & 153,5 & 133,7 & 3,33 & 0,7399 \\
\hline$B X-10$ & 3896 & 146,4 & 142,9 & 2,98 & 0,7393 \\
\hline BY -8 & 3954 & 185,4 & 92,8 & 5,81 & 0,7602 \\
\hline$B Z-2$ & 3955 & 126,7 & 82,9 & 4,45 & 0,7551 \\
\hline CY-1 & 3958 & 132,4 & 53,3 & 7,24 & 0,7764 \\
\hline $\mathrm{CY}-4$ & 3959 & 48,6 & $182, \mathrm{i}$ & 0,77 & 0,7174 \\
\hline CY.5 & 3960 & 146,6 & 53,1 & 8,05 & 0,7844 \\
\hline$C Y-6$ & 3961 & 57,8 & 61,3 & 2,74 & 0,7373 \\
\hline $\mathrm{DX}-2$ & 3897 & 97,2 & 130,9 & 2,16 & 0,7458 \\
\hline DX-3 & 3898 & 144,5 & 67,8 & 6,22 & 0,7859 \\
\hline DX-4 & 3899 & 55,8 & 189,0 & 0,86 & 0,7341 \\
\hline$D X-6$ & 3900 & 103,2 & 79,0 & 3,80 & 0,7627 \\
\hline $\mathrm{EX}-2$ & 3963 & 63,3 & 177,2 & 1,04 & 0,7221 \\
\hline EY-5 & 3964 & 68,8 & 133,5 & 1,49 & 0,7253 \\
\hline $\mathrm{J}-4$ & 3953 & 91,3 & 67,9 & 3,91 & 0,7456 \\
\hline $\mathrm{J} \sim 13$ & 3983 & 156,8 & 47,8 & 9,53 & 0,8023 \\
\hline $\mathrm{J}-20$ & 3956 & 153,9 & 52,6 & 8,54 & 0,7855 \\
\hline $\mathrm{J}-24$ & 3957 & 90,8 & 85,6 & 3,08 & 0,7414 \\
\hline M-14 & 3986 & 187,4 & 30,4 & 18,17 & 0,9586 \\
\hline M-36 & 3987 & 190,6 & 16,9 & 33,37 & 1,0837 \\
\hline R-1 & 3984 & 156,6 & 36,6 & 12,45 & 0,8212 \\
\hline$R-3$ & 3985 & 168,3 & 31,7 & 15,43 & 0,8356 \\
\hline$R-4$ & 3962 & 150,1 & 50,8 & 8,63 & 0,7934 \\
\hline$V_{-11}$ & 3989 & 164,5 & 40,2 & 11,92 & 0,8628 \\
\hline
\end{tabular}

Tabela 3 - Resultados de análises isotópicas de chumbo em amostra-padrão galena de Broken Hill (T-1003)

\begin{tabular}{|c|c|c|c|}
\hline & $\mathrm{Pb}^{206} / \mathrm{Pb}^{204}$ & $\mathrm{~Pb}^{207} / \mathrm{Pb}^{204}$ & $\mathrm{~Pb}^{208} / \mathrm{Pb}^{204}$ \\
\hline $\begin{array}{l}\text { Cooper et al. (1969) } \\
\text { (normalizado) }\end{array}$ & 16,003 & 15,39 & 35.660 \\
\hline $\begin{array}{l}\text { Stacey et al. (1969) } \\
\text { (absoluto) }\end{array}$ & $.16,012$ & 15,398 & 35.682 \\
\hline $\begin{array}{l}\text { Geol. Survey of Canadá (1971) } \\
\text { (citado em Thorpe, 1974) }\end{array}$ & $\begin{array}{l}16,000 \\
\pm 0,1\end{array}$ & $\begin{array}{l}15,408 \\
\pm 0,14\end{array}$ & $\begin{array}{r}35,71 \\
\pm 0,46\end{array}$ \\
\hline $\begin{array}{l}\text { Geol. Survey of Canadá (1972) } \\
\text { (citado em Thorpe, 1974) }\end{array}$ & $\begin{array}{r}15,91 \\
\pm 0,07\end{array}$ & $\begin{array}{r}15,26 \\
\pm 0,11\end{array}$ & $\begin{array}{r}35,71 \\
\pm 0,31\end{array}$ \\
\hline $\begin{array}{l}\text { Este trabalho } \\
\text { (método da sílica-gel e monofilamento) }\end{array}$ & $\begin{array}{r}16,11 \\
\pm 0,08\end{array}$ & $\begin{array}{r}15,50 \\
\pm 0,09\end{array}$ & $\begin{array}{r}35,51 \\
\pm 0,26\end{array}$ \\
\hline $\begin{array}{l}\text { Este trabalho } \\
\text { (filamento duplo) }\end{array}$ & $\begin{array}{r}15,94 \\
\pm 0,06\end{array}$ & $\begin{array}{r}15,35 \\
\pm 0,08\end{array}$ & $\begin{array}{r}35,59 \\
\pm 0,21\end{array}$ \\
\hline
\end{tabular}


Tabela 4 - Análises da composição isotópica do chumbo em galenas

\begin{tabular}{|c|c|c|c|c|}
\hline $\begin{array}{c}\text { Amostra } \\
\text { n? }\end{array}$ & $206 \mathrm{~Pb} / 204 \mathrm{pb}$ & ${ }^{207} \mathrm{~Pb} /{ }^{204} \mathrm{~Pb}$ & ${ }^{208} \mathrm{~Pb} /{ }^{204} \mathrm{~Pb}$ & Ref. \\
\hline $\mathrm{v}_{3}$ & 17,85 & 15,81 & 37,39 & 1 \\
\hline$v_{1}$ & 17,68 & 15,62 & 37,06 & 1 \\
\hline$v_{2}$ & 17,64 & 15,56 & 37,06 & 1 \\
\hline$I_{i}$ & 20,30 & 16,10 & 40,90 & 1 \\
\hline $\mathrm{I}_{2}$ & 20,54 & 16,36 & 41,56 & 1 \\
\hline $\mathrm{T}$ & 19,60 & 15,85 & 38,87 & 1 \\
\hline $\mathrm{F}$ & 19,06 & 15,90 & 38,99 & 1 \\
\hline DP60 & $17,61 \pm 0,03$ & $15,59 . \pm 0,02$ & $36,90 \pm 0,06$ & 2 \\
\hline DP61 & $19,02 \neq 0,11$ & $15,52 \pm 0,10$ & $37,63 \pm 0,20$ & 2 \\
\hline DP68 & $19,34 \pm 0,06$ & $15,78 \pm 0,04$ & $38,34 \pm 0,10$ & 2 \\
\hline DP63 & $19,95 \pm 0,05$ & $16,00 \pm 0,04$ & $39,53 \pm 0,10$ & 2 \\
\hline DP69 & $19,96 \pm 0,06$ & $16,10 \pm 0,05$ & $39,45 \pm 0,11$ & 2 \\
\hline DP62 & $19,86 \pm 0,05$ & $15,86 \pm 0,04$ & $38,98 \pm 0,08$ & 2 \\
\hline DP74 & $19,92 \pm 0,06$ & $15,96 \pm 0,05$ & $39,21 \pm 0,13$ & 2 \\
\hline MM1 & $19,72 \pm 0,09$ & $15,79 \pm 0,06$ & $38,55 \pm 0,16$ & 3 \\
\hline MM2 & $20,24 \pm 0,11$ & $15,94 \pm 0,07$ & $40,09 \pm 0,13$ & 3 \\
\hline MM3 & $20,02 \pm 0,10$ & $15,93, \pm 0,08$ & $39,85 \pm 0,18$ & 3 \\
\hline MM4 & $19,83 \pm 0,09$ & $15,85 \pm 0,06$ & $93,05 \pm 0,14$ & 3 \\
\hline MM5 & $18,92 \pm 0,07$ & $15,83 . \pm 0,07$ & $38,64 \pm 0,18$ & 3 \\
\hline MM6 & $18,94 \pm 0,09$ & $15,80 \pm 0,08$ & $38,48 \pm 0,22$ & 3 \\
\hline MM7 & $24,87 \pm 0,11$ & $16,29 \pm 0,09$ & $46,05 \pm 0,29$ & 3 \\
\hline MM8 & $36,43 \pm 0,20$ & $18,21 \pm 0,09$ & $45,63 \pm 0,30$ & 3 \\
\hline MM9 & $20,52 \pm 0,10$ & $15,48 \pm 0,07$ & $43,93 \pm 0,27$ & 3 \\
\hline MM10 & $17,95 \pm 0,09$ & $15,29 \pm 0,06$ & $37,21 \pm 0,18$ & 3 \\
\hline MM11 & $18,92 \pm 0,09$ & $15,75 \pm 0,05$ & $37,95 \pm 0,15$ & 3 \\
\hline MM12 & $32,12 \pm 0,19$ & $17,69 \pm 0,08$ & $44,93 \pm 0,35$ & 3 \\
\hline MM13 & $17,69 \pm 0,08$ & $15,57 \pm 0,08$ & $36,89 \pm 0,27$ & 3 \\
\hline MM14 & $17,79 \pm 0,07$ & $15,60 \pm 0,08$ & $36,98 \pm 0,24$ & 3 \\
\hline MM15 & $17,91 \pm 0,08$ & $15,81 \pm 0,07$ & $37,60 \pm 0,25$ & 3 \\
\hline MM16 & $18,91 \pm 0,09$ & $15,62 \pm 0,08$ & $37,89 \pm 0,22$ & 3 \\
\hline MM17 & $19,13 \pm 0,09$ & $15,82 \pm 0,08$ & $38,54 \pm 0,23$ & 3 \\
\hline
\end{tabular}

1 - Amaral (1968)

2 - Cassedanne e Lasserre (1969)

3 - Este trabalho

razão inicial obtida é perfeitamente compatível com o modelo exposto.

$\mathrm{Na}$ Fig. 2 foi situado o ponto analítico relativo à amostra AX-2, coletado a $10 \mathrm{~km}$ para o norte do aflora* mento anterior mas de composição muito similar. Sua posição, praticamente sobre a isócrona traçada, indica sua co-geneticidade em relação às amostras AY. Por outro lado, as amostras $\mathrm{J}-4$ e $\mathrm{J}-13$ representam argilitos com aspecto um tanto diferente, com predominância de ilitas e com menos clorita na composiçåo. Provêm de unidades com posição estratigráfica similar à da Formação Pirapora, em Arinos e ao norte de João Pinheiro. Em ambos os casos, os pontos analíticos situam-se acima da isócrona das amostras de Pirapora. Como só foi efetuada uma determinação de cada sítio, não é possivel verificar o respectivo padrão geocronológico. É evidente entretanto que, embora as amostras J-4 e J-13 possuăm a mesma idade que as de Pirapora, sua razão inicial deve ter sido muito mais elevada, o que indicaria fontes de material diferentes detríticos relativamente mais importantes.

A Fig. 3 apresenta o diagrama isocrônico relativo às amostras da Formação Três Marias. Quatro amostras coletadas nas proximidades de Felixlầndia $(\mathrm{BX}-3, \mathrm{BX}-8$, BX-9 e BX-10), de um mesmo afloramento, indicaram uma isócrona de $620 \pm 40 \mathrm{~m}$.a. com razão inicial $\mathrm{Sr}^{87} / \mathrm{Sr}^{86}$ de 0,7125 . Neste caso, as rochas são siltitos arcoseanos, cuja mineralogia principal é detrítica e consiste em quartzo, feldspatos, ilita e clorita, como no caso das amostras de Pirapora. No mesmo diagrama isocrônico foram incluídos os pontos analíticos de quatro outras amostras da mesma formação, coletadas em afloramentos diferentes, $10 \mathrm{~km}$ NE de Felixlândia (BY-8), no rio Abaeté (BZ-2), em.Três Marias (J-24) e em Pirapora (J-20). A composição de todas elas foi essencialmente a mesma que as amostras de Felixlândia e todos os pontos analíticos mostraram-se muito próximos da isócrona traçada. Tendo em vista que em ne- 


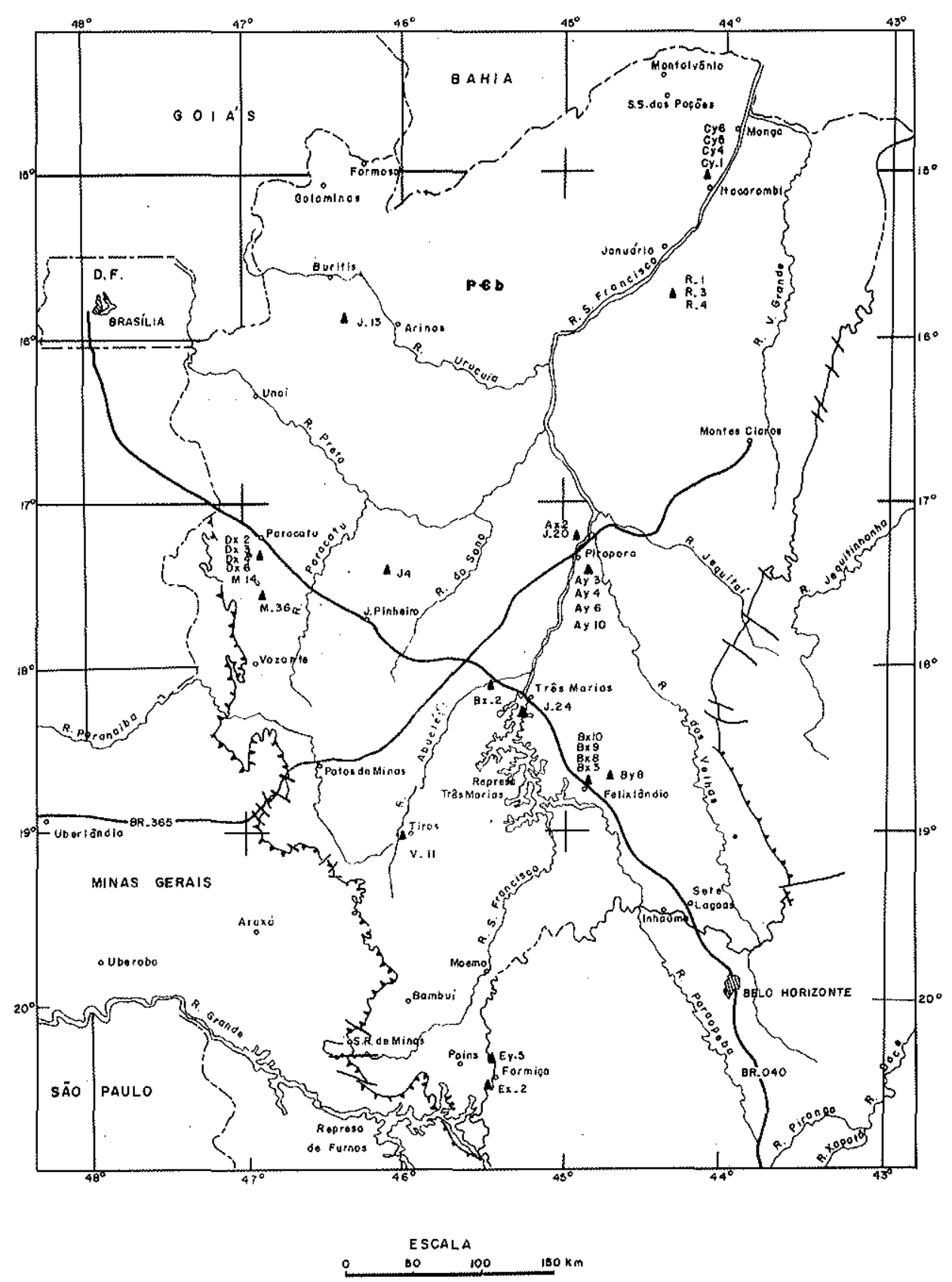

LE GENDA

- ponto de amostragem

- cIOADE

ROOOVIA

LIMITES DO GRUPO BAMQUI ( PED) CONFORME MAPA GEOLÓGICO DO EST. LE MINAS GERAIS - IGA. 1976 METAIS DE MINAS GERAIS S.A. 


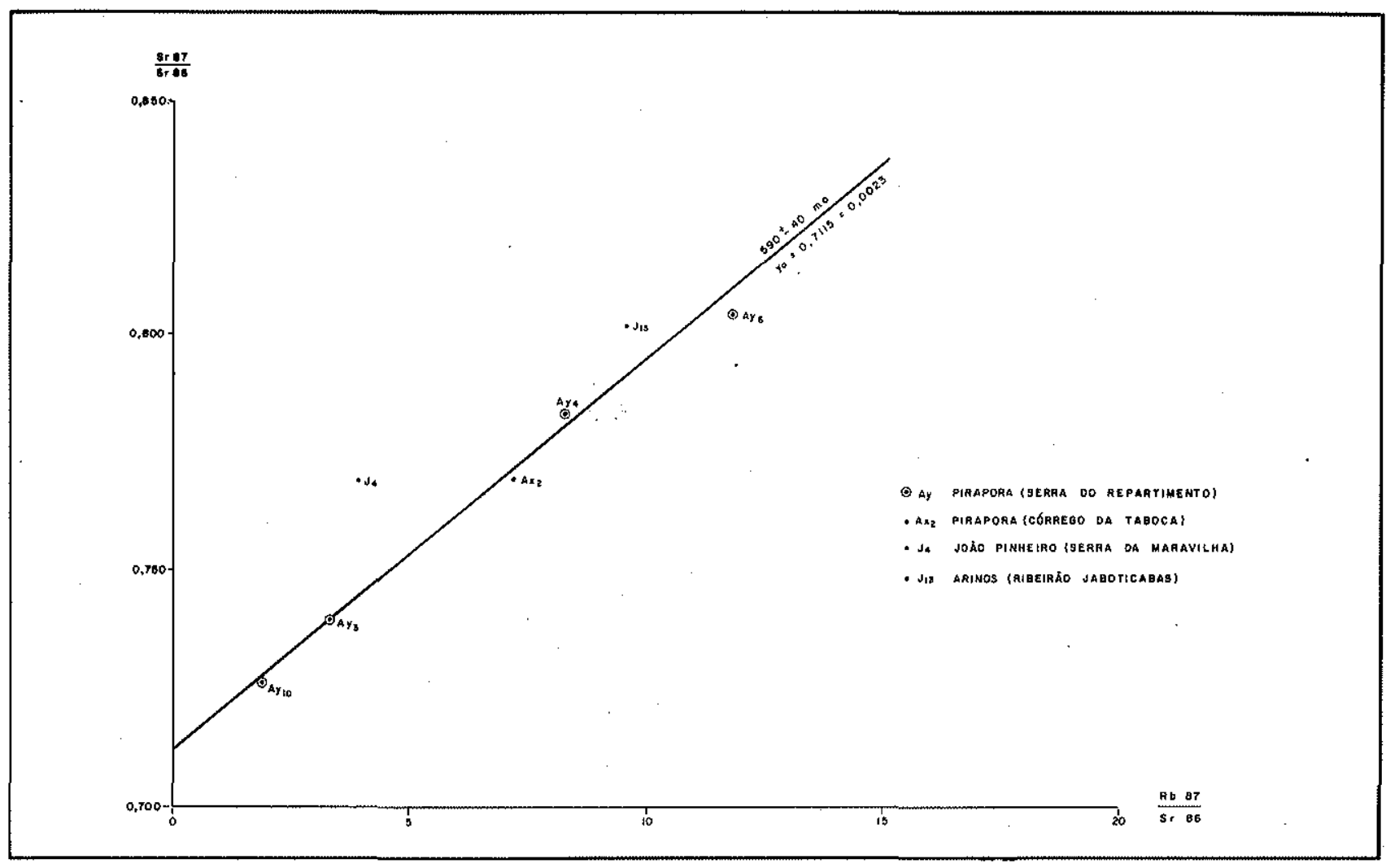

Figura 2 - Diagrama isocrônico: Formação Pirapora

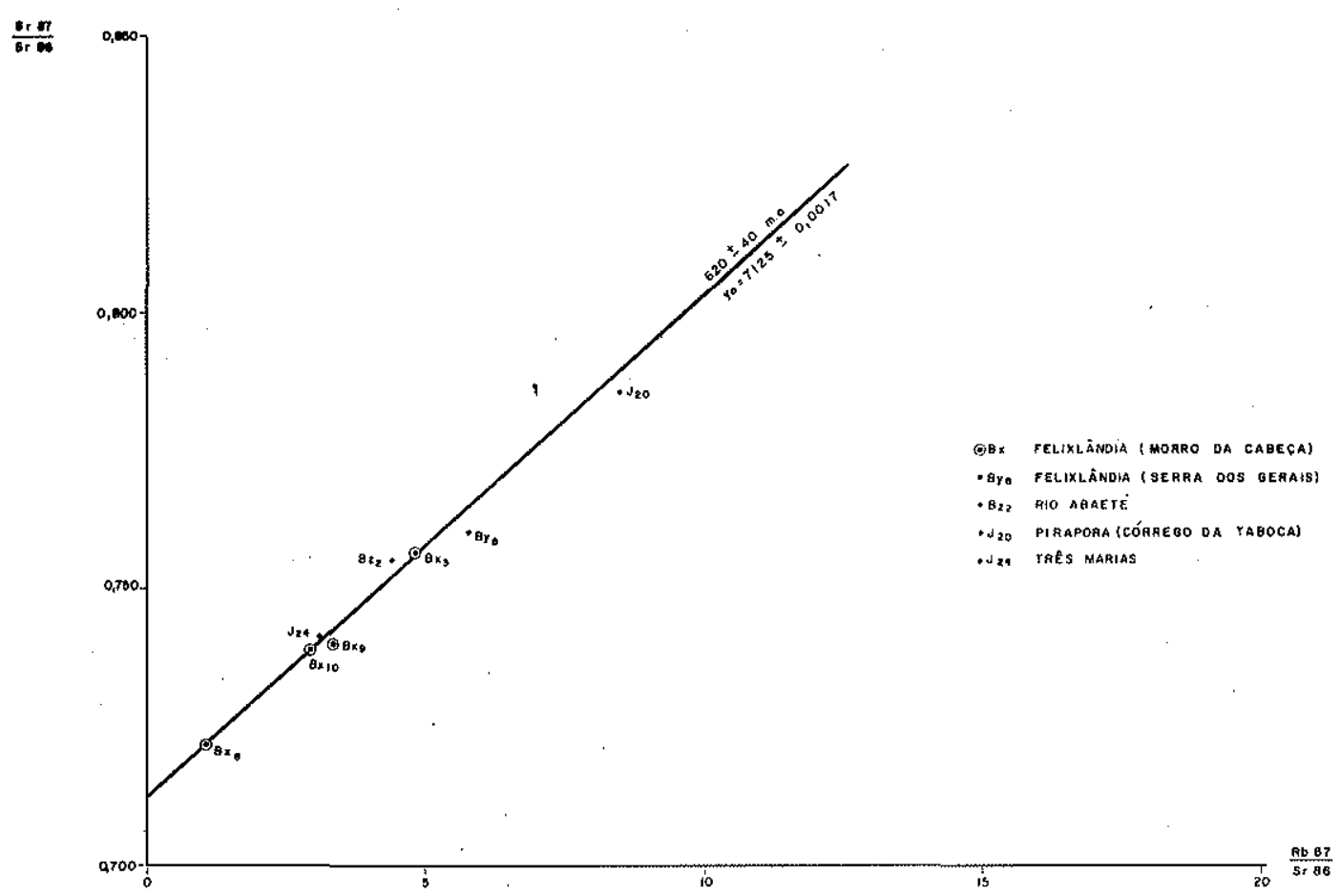

Figura 3 - Diagrama isocrônico: Formação Três Marias 


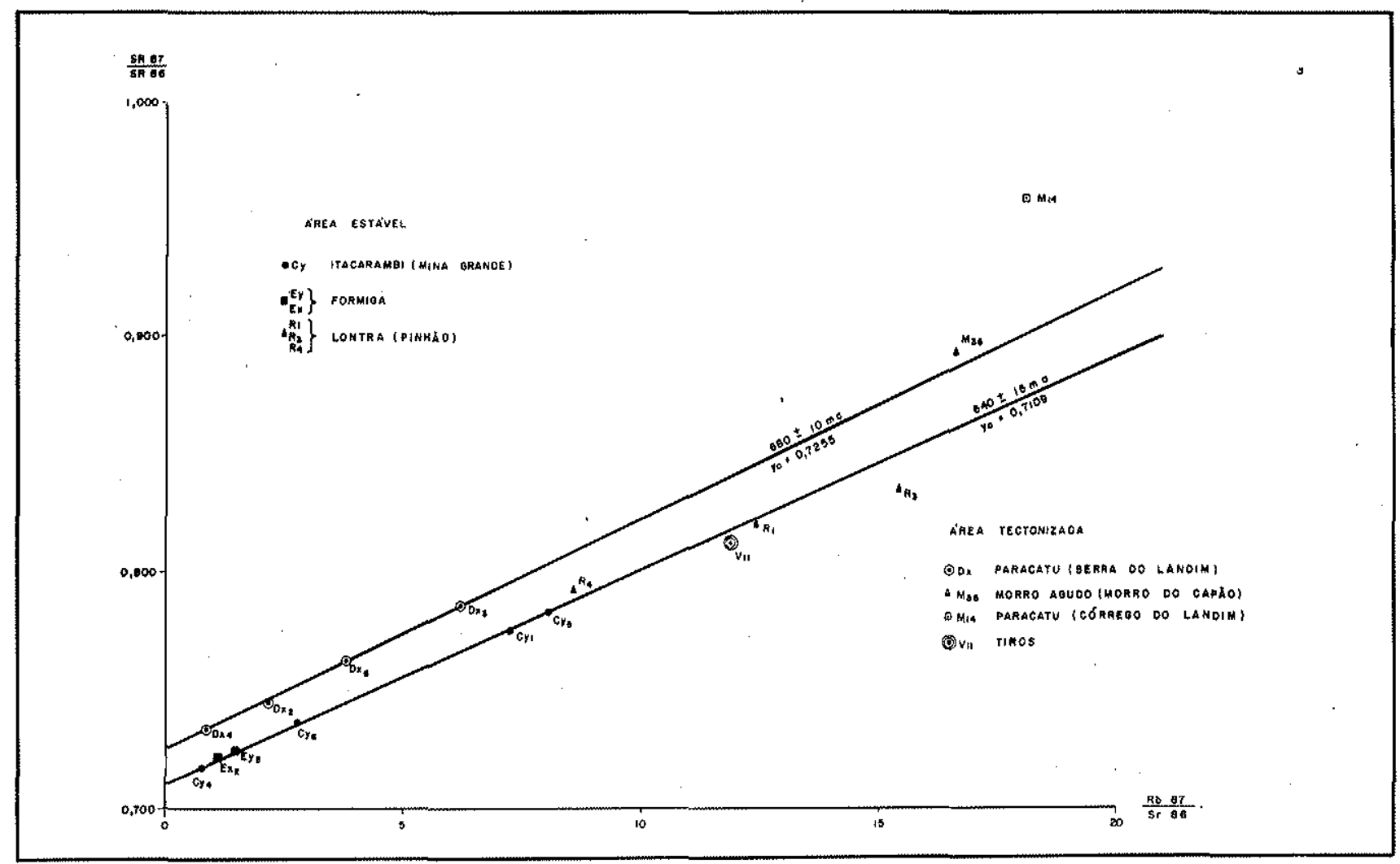

Figura 4 - Diagrama isocrônico: Formação Paraopeba

nhum caso aparecem sinais de tectonismo e/ou metamorfismo, aqui também a idade obtida pode ser interpretada como a época de deposição, segundo as idéias de Cordani et al. (1978). De novo, a razão inicial obtida, $\mathrm{Sr}^{87} / \mathrm{Sr}^{86}=0,7125$, é perfeitamente compativel com o modelo exposto.

A Fig. 4 apresenta os dados relativos à Formação $\mathrm{Pa}$ raopeba. $O$ exame da ilustração mostra desde logo que podem ser traçadas duas isócronas com idade e razão inicial próprias, características e distintas entre si.

Quatro amostras de siltitos, coletadas de um mesmo afloramento nas proximidades de Itacarambi (CY-1, CY-4, CY-5 e CY-6), definiram uma isócrona de boa qualidade, com $640 \pm 15$ m.a. e razåo inicial $\mathrm{Sr}^{87} / \mathrm{Sr}^{86}$ $=0,7109$. No difratograma, a mineralogia evidenciada continuou muito similar à das demais formaçoes (basicamente quartzo, ilita e clorita, além de feldspatos detríticos e alguns carbonatos presentes na amostra CY-4). Três outras amostras de afloramento coletadas na mesma região setentrional mineira (R1, R3 e R4) apresentaram pontos analíticos relativamente próximos da isócrona mencionada, podendo ser considerados relacionados. Nessas amostras, interestratificados cloritavermiculita apareceram em lugar da clorita. E interessante notar que também as amostras EX-2 e EY-5, coletadas em afloramentos diferentes da região de Formiga, na extremidade sul da área de ocorrência do Grupo Bambui, dispuseram-se praticamente sobre a mencionada isócrona de $640 \pm 15$ m.a. Essas amostras represen- tam sedimentos clástico-químicos, contendo essencialmente calcita, quartzo, ilita, algo de clorita e smectitas, sem que tenha sido identificàda a presença de feldspatos nos difratogramas.

Em todos esses casos, as amostras não apresentam qualquer importante evidência de metamorfismo, tendo sido coletadas em região estável do ponto de vista tectônico. Aqui também, como nos casos anteriormente consultados, é possível, segundo o modelo proposto por Cordani et al. (1978), relacionar a idade de $640 \pm 15$ m.a. com a época da deposição dos sedimentos da Formação Paraopeba, estando o valor relativamente baixo da razão inicial $(0,7109)$ plenamente compatível com essa interpretação.

Isócrona completamente diferente pode ser traçada pelos pontos DX-2, DX-3, DX-4 e DX-6 de sedimentos clásticoquímicos coletados de um mesmo afloramento, nas proximidades de Paracatu, no oeste mineiro. Nas quatro amostras, a mineralogia revelou-se muito similar, aparecendo essencialmente quartzo, dolomita, feldspatos, ilita e clorita, com calcita adicional nas amostras DX-2 e DX-4. A isócrona traçada, de muito boa qualidade devido ao excelente alinhamento dos pontos analíticos no diagrama (Fig. 4), apresentou idade de $680 \pm 10$ m.a. e razão inicial $\mathrm{Sr}^{87} / \mathrm{Sr}^{86}$ de 0,7255 .

As amostras apresentam aspecto bastante diferente das demais, com certa clivagem tectônica evidente, mostrando sua proveniêncla de área tectonizada. Em vista disso, a idade obtida deve ser interpretada segundo o 
modelo anqui/epimetamórfico (modelo IV) de Cordani et al. (1978), no qual a isócrona resulta de uma re-homogeneização isotópica ocorrida durante o metamorfismo. A razão inicial elevada é indicação adicional sugestiva para uma interpretação desse tipo. Dessa forma, é necessário atribuir uma idade deposicional anterior a 680 m.a. para as amostras da região de Paracatu, tornando difícil è até mesmo improvável sua correlação com as demais amostras datadas neste trabalho (Itacarambi e Formiga) e que têm sido consideradas como pertencentes à mesma formação Paraopeba.

Três outras amostras (M-14, M-36 e V-11), provenientes da área ocidental, tectonizada, do Grupo Bam. bui, podem ser consideradas no mesmo diagrama isocrônico da Fig. 4. Uma delas, M-36, coletada a cerca de $50 \mathrm{~km}$ ao sul de Paracatu, situa-se praticamente sobre a isócrona de 680 m.a., indicando possivelmente sua co-geneticidade em relação às amostras DX. A situação do ponto no diagrama analítico, com razão $\mathrm{Rb}^{87} / \mathrm{Sr}^{86}$ muito elevada, deve-se à mineralogia presente (quartzoilita-clorita), sem carbonatos nem feldspatos detríticos. A amostra M-14 (mesma localidade que o afloramento DX, mas em diferente nível estratigráfico) apresentou ponto analítico situado muito acima da isócrona de 680 m.a., talvez por causa de uma razao inicial ainda mais elevada que 0,7255 . Por outro lado, a amostra V-11, um siltito tectonizado da regiåo de Tiros, apresentou ponto analítico situado bem abaixo da isócrona de 680 m.a., sugerindo remobilizações químicas ocorridas posteriormente. Interpretaçðes mais esclarecedoras a respeito da evolução dessas amostras isoladas só poderão ser tentadas quando forem disponíveis dados geocronológicos adicionais das respectivas áreas de ocorrência.

Resumindo as informaçðes expostas neste capítulo, é possível sugerir os seguintes eventos geológicos para as sequiências datadas:

- Formação Paraopeba em Paracatu, tectonizada: metamorfismo com $680 \pm 10$ m.a.

- Formação Paraopeba, em Itacarambi e Formiga, estável: deposição em $640 \pm 15$ m.a.

- Formação Três Marias, em Felixlândia, estável: deposição em $620 \pm 40$ m.a.

- Formação Pirapora, em Pirapora, estável: deposição em $590 \pm 40 \mathrm{~m}$.a.

\section{DISCUSSÃo DOS DADOS ISOTÓPICA DE CHUMBO}

DE COMPOSIÇÃo

As galenas analisadas no presente trabalho provieram de diferentes localidades situadas em todos os quadrantes da ocorrência do Grupo Bambuí no Estado de Minas Gerais (Fig. 5). As ocorrências podem ser classificadas em três tipos: veios, depósitos estratificados e depósitos alterados, não havendo em qualquer dos càsos associação do chumbo com minerais de ferro. Em certos casos, aparecem fenômenos de dolomitização e de silicificação das rochas encaixantes enquanto os minérios encontram-se geralmente oxidados.

Os dados isotópicos do chumbo foram lançados em dois diagramas que incluem as curvas de evoluçåo isotópica do chumbo (Figs. 6 e 7) conforme o modelo III, de estágio simples, preconizado por Cumming e Richards (1975). Conforme pode ser verificado na Fig. 6 , em que as razð̄es $\mathrm{Pb}^{207} / \mathrm{Pb}^{204}$ são relacionadas com as razóes $\mathrm{Pb}^{206} / \mathrm{Pb}^{204}$, a maioria das relaçōes isotópicas das galenas analisadas apresenta-se anômala, situandose à direita da isócrona de zero m.a. e, portanto, suas idades aparentes $\mathrm{Pb}$-modelo são negativas, ou do tipo " J"' (idades futuras), tal como apresentam Cassedanne e Lasserre (1969), e Cassedanne (1973). Apenas aquelas relativas às regióes de Vazante e Paracatu (MM 13, MM 14, MM 15, V1, V2, V3 e DP 60) situaram-se mais ou menos próximas da curva de evolução isotópica de $\mathrm{Pb}$, no trecho próximo da idade de 600 m.a. As idades aparentes dessas galenas, se calculadas segundo o modelo preconizado de evolução isotópica linear (Cumming e Richards, 1975), apresentariam valores relativamente concordantes conforme indica a tabela.

Uma idade-modelo "média", da ordem de $650 \pm 50$ m.a., pode ser inferida pelo exame da Tab. 5 para 0 chumbo das galenas da regiăo de Vazante e Paracatu, pelo menos em relação aos valores calculados segundo

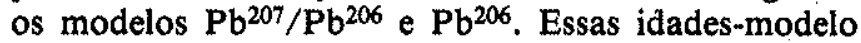
concordam, em ordem de grandeza, com as idades $\mathbf{R b}$ Sr em rocha total obtidas para rochas da mesma área, como pode ser verificado pelos dados do capítulo anterior ou no trabalho de Amaral e Kawashita (1967).

A Fig. 6 mostra também que as razðes isotópicas do chumbo exibem nítida correlação linear com as exceçðes apresentadas pelos dados das galenas MM 7, MM 9 e MM 10. A reta que melhor se ajusta aos pontos analíticos, traçada por regressão segundo o método de York (1969), apresenta uma inclinação de $0,137 \pm 0,005$ e intercepta a curva de crescimento isotópico em dois pontos, $600 \pm 50$ m.a. e $2000 \pm 100$ m.a. O valor de 600 m.a. apresenta-se em concordância com as idades-modelo das galenas de Vazante e Paracatu (Tab. 5) e com as idades isocrônicas $\mathrm{Rb}-\mathrm{Sr}$ já discutidas. $\mathrm{O}$ valor de $2000 \mathrm{~m}$.a. coincide com o intervalo de tempo característico do ciclo tecto-orogênico Transamazônico definido por Hurley et al., 1967.

Dessa forma, pode ser sugerido que o chumbo associado ao Grupo Bambuí, de um modo geral, tenha evoluído em dois estágios principais. No primeiro, sua composição isotópica teria evoluído de forma simples, no manto, até a época de $2000 \mathrm{~m}$.a. Nesta época teria corrido sua separação do manto e introdução na crosta, o que acarretaria sua conseqüente associação a materiais de diferentes relaçóes $\mathrm{U} / \mathrm{Pb}$. O segundo estágio evolutivo teria acarretado o crescimento das razóes isotópicas do chumbo segundo a reta traçada na Fig. 6, e essa evolução teria terminado há cerca de $600 \mathrm{~m}$.a. quando o chumbo teria sido incorporado definitivamente nas galenas. Ao que parece, o evento deposicional do Grupo Bambuí não teria qualquer relação direta com a evolução isotópica em questão.

$\mathrm{Na}$ Fig. 7, em que são relacionados os valores da razão $\mathrm{Pb}^{208} / \mathrm{Pb}^{204}$ com os valores $\mathrm{Pb}^{206} / \mathrm{Pb}^{204}$, aparecem representadas as relaçðes isotópicas correspondentes ao chumbo toriogênico (derivado do tório), as quais se apresentam anômalas em sua maioria com os pontos analíticos situados à direita da isócrona zero m.a., como no caso anterior.

Esse fato sugere um padrão típico de mistura de chumbos anômaḷos desenvolvidos em sistemas abertos. Também na Fig. 7 aparece uma clara tendência linear 


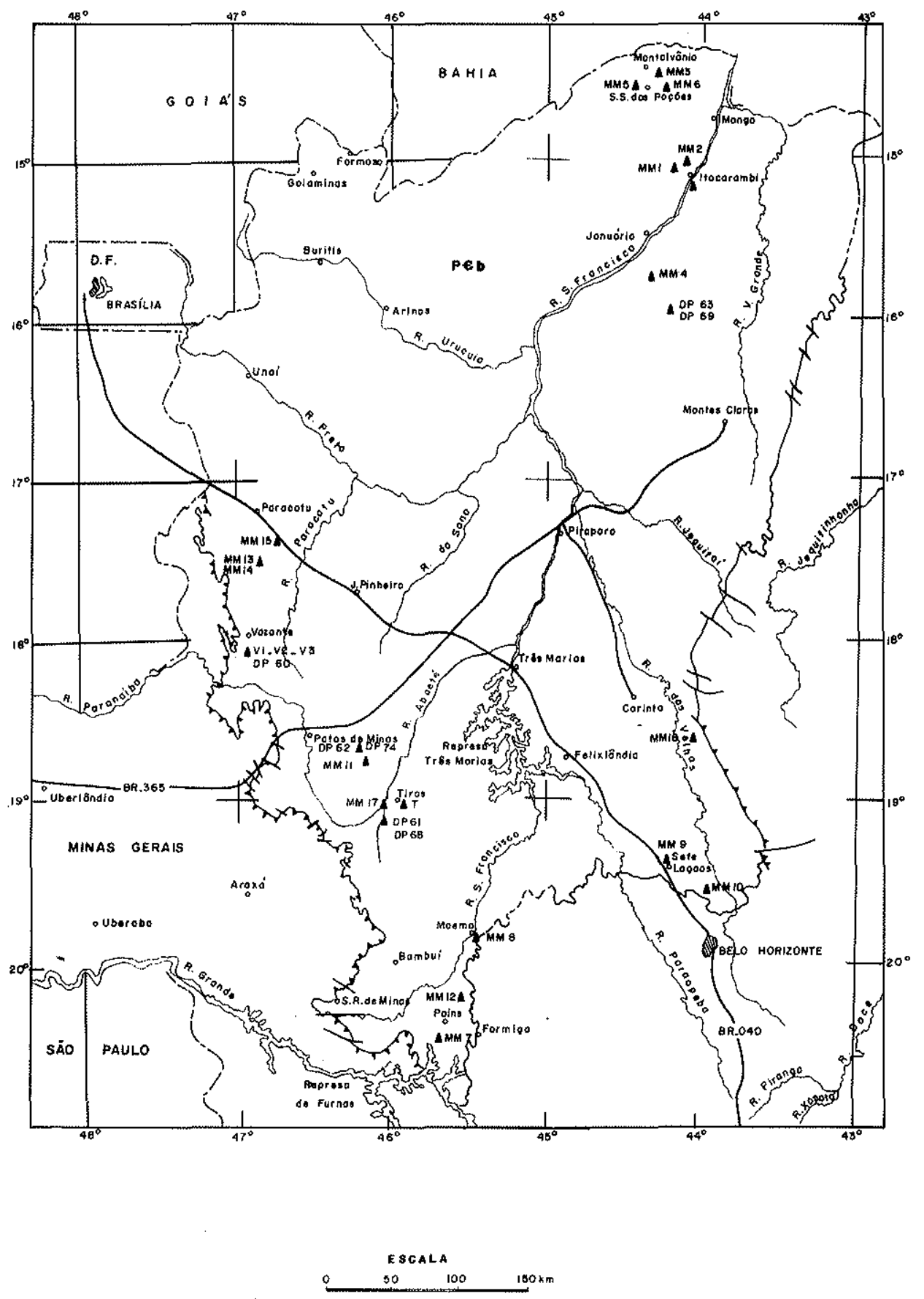

LEGENDA

a ponto de amostragem

- cloade

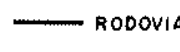

LIMITES DO ORUPO BAMBUI $(P E b)$ CONFORME

MAPA GEOLO'GICO DO EST, DE MINAS GERAIS - IGA. 1976 


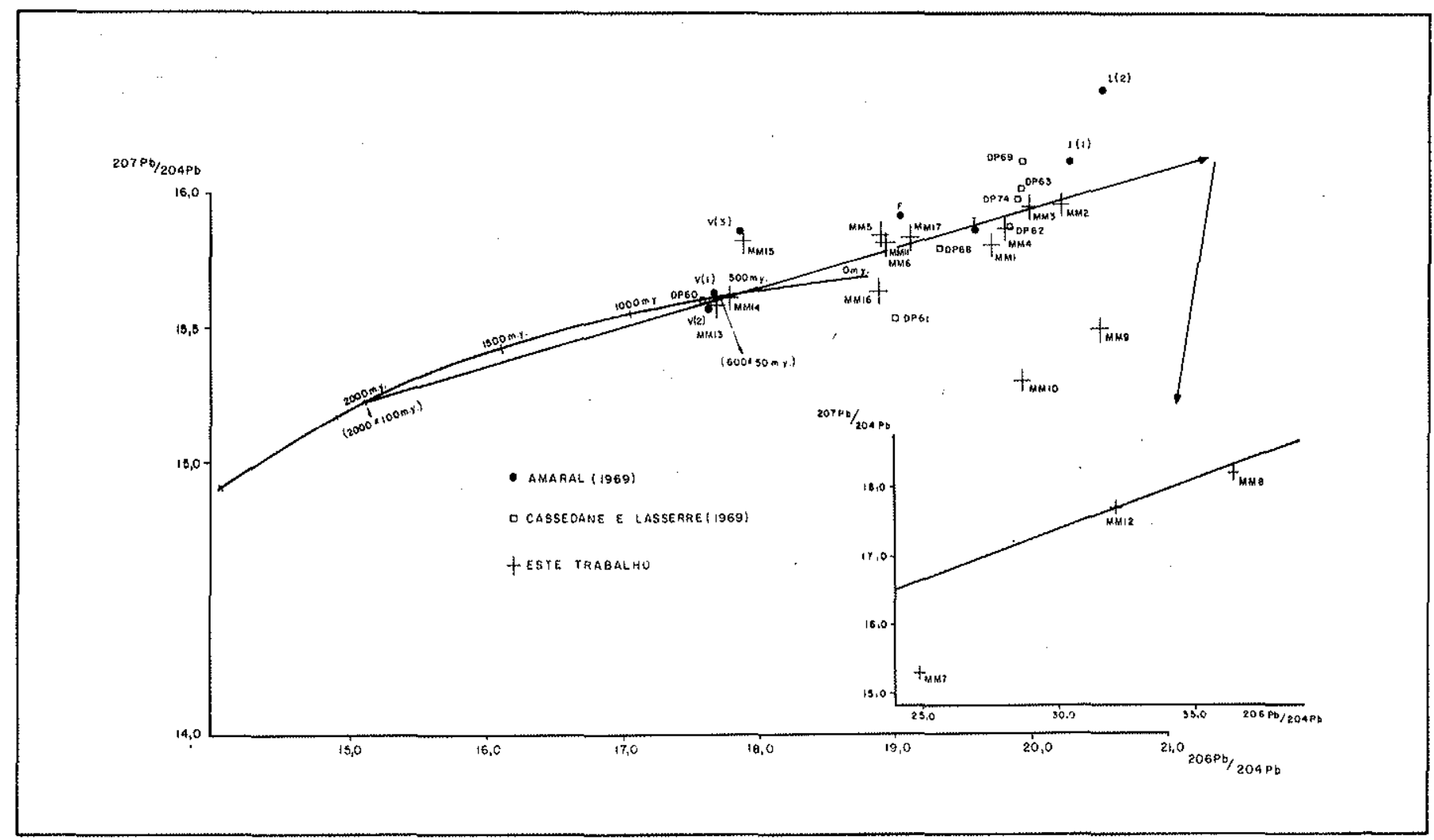

Figura 6 - Diagrama da evolução isotópica do chumbo: $\mathrm{Pb}^{207 / 204}$ versus. $\mathrm{Pb}^{206 / 204}$

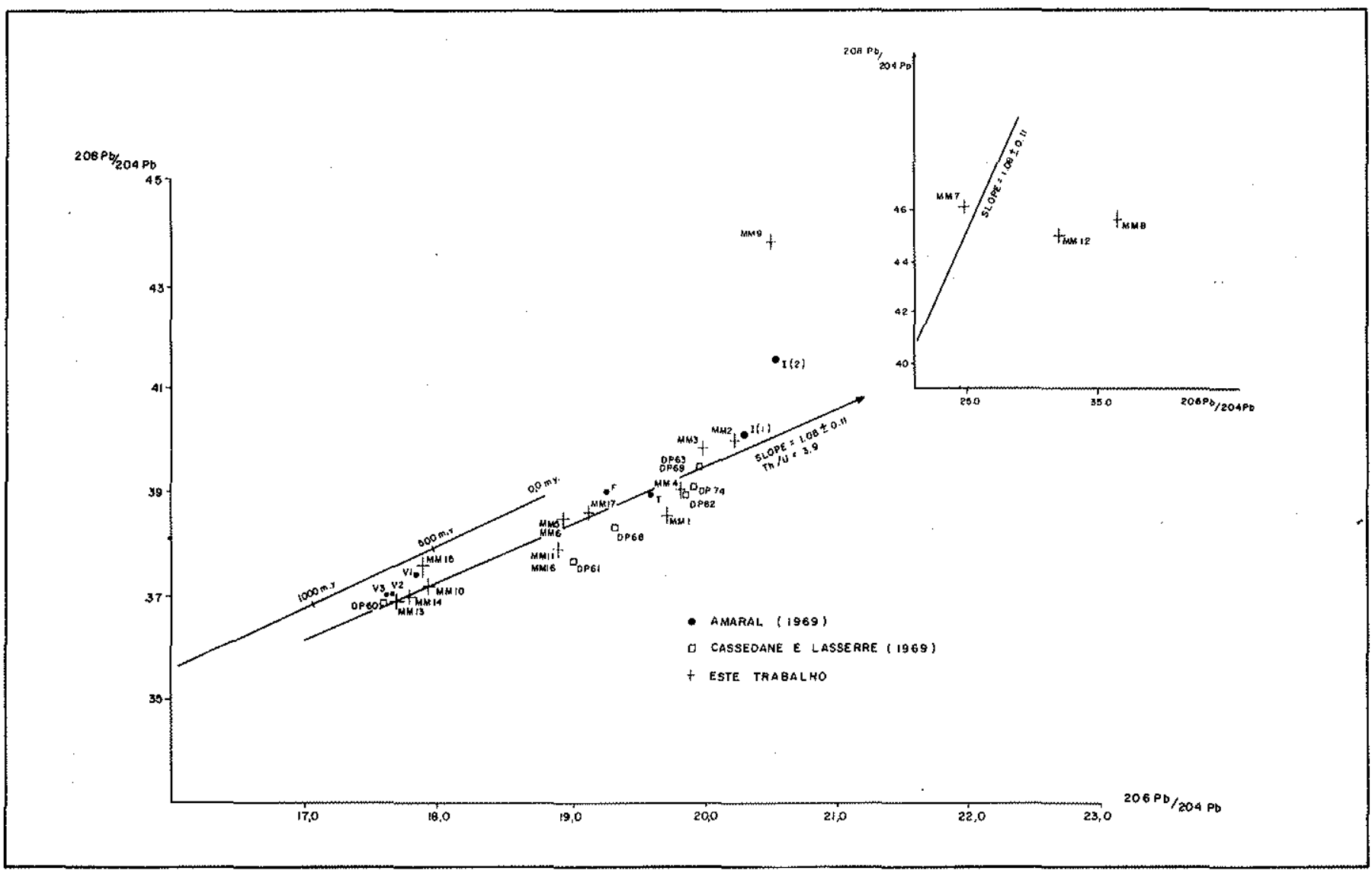

Figura 7 - Diagrama da evolução isotópica do chumbo: $\mathrm{Pb}^{208 / 204}$ versus ${ }^{206 / 204}$ 
Tabela 5 - Idades-modelo III (Cumming e Richards, 1975) de galenas da região de Paracatu e Vazante

\begin{tabular}{|c|c|c|c|c|}
\hline $\begin{array}{c}\text { Amostra } \\
n ?\end{array}$ & Referência & $\begin{array}{c}\text { Idade } \\
207 \mathrm{~Pb} / 206 \mathrm{~Pb} \\
\text { m.a. }\end{array}$ & $\begin{array}{c}\text { Idade } \\
206 \mathrm{~Pb} / \mathrm{Pb}^{204} \\
\text { m.a. }\end{array}$ & $\begin{array}{c}\text { Idade } \\
{ }^{208} \mathrm{~Pb} / \mathrm{Pb}^{204} \\
\mathrm{~m} . \mathrm{a} .\end{array}$ \\
\hline VI & Amaral (1968) & 750 & 560 & 750 \\
\hline v2 & Amaral (1968) & 650 & 650 & 850 \\
\hline V3 & Amaral (1968) & 650 & 650 & 850 \\
\hline \multirow[t]{2}{*}{ DP60 } & Cassedanne e & & & \\
\hline & Lasserre (1969) & 650 & 650 & 950 \\
\hline MMI3 & Este trabalho & 630 & 660 & 980 \\
\hline MM14 & Este trabalho & 600 & 600 & 970 \\
\hline MM15 & Este trabalho & 730 & 550 & 630 \\
\hline
\end{tabular}

para a distribuição dos pontos e a inclinação calculada para a melhor reta traçada por regressão é a de $1,08 \pm 0,11$. O valor da razão $\mathrm{Th} / \mathrm{U}$ calculado para $\mathrm{o}$ material-fonte é de 3,9 $\pm 0,3$. A disposiçåo linear dos pontos é indicativa de que o chumbo das ocorrências de galena da região foi incorporado a um ambiente crustal em que os materiais apresentavam razōes similares $\mathrm{Th} / \mathrm{U}$. Considerando-se todas as análises efetuadas e as disponíveis na literatura especializada, e calculando-se os valores $\mathrm{U} / \mathrm{Pb}$ e $\mathrm{Th} / \mathrm{Pb}$ obtidos para cada caso, para o material-fonte do chumbo, foram encontrados os seguintes intervalos de variação:

$$
\begin{aligned}
& \mathrm{U}^{238} / \mathrm{Pb}^{204}: \text { de } 9,7 \text { a } 80,1 \\
& \mathrm{U}^{235} / \mathrm{Pb}^{204}: \text { de } 0,06 \text { a } 5,4 \\
& \mathrm{Th}^{232} / \mathrm{Pb}^{204} \text { : de } 29 \text { a } 152
\end{aligned}
$$

Essas razões, de um modo geral, apresentam-se superiores às apresentadas por chumbos atuais, que evoluíram segundo estágio simples, no manto, conforme o modelo mencionado, de Cumming e Richards, 1975.

Os presentes autores consideram que a sistemática isotópica do chumbo do Grupo Bambuí ajusta-se melhor a um esquema de evolução em duplo estágio, em que a separação final e a incorporação nas galenas teriam ocorrido durante uma ou mais fases tectônicas do Ciclo Brasiliano, a partir de um material fonte crustal, e referente ao embasamento do Grupo Bambuí. Esse embasamento teria idade provável transamazônica ou, alternativamente, teria sido intensamente afetado por episódios transamazônicos acompanhados de introdução de chumbo juvenil.

\section{CONCLUSÕES SOBRE A IDADE E A EVOLUÇÃo} GEOLÓGICA DO GRUPO BAMBUí Pelo exposto no capítulo relativo à discussão das determinações $\mathrm{Rb}-\mathrm{Sr}$, foi possivel indicar a época provável dos episódios de sedimentação/diagênese precoce no caso das formações Paraopeba, Três Marias e Pirapora da região tectonicamente estável do Grupo Bambuí. A seqüência dos valores encontrados $(640 \pm 15,620 \pm 40$ e $590 \pm 40$ m.a. $)$, embora exista certo recobrimento face aos erros experimentais apontados, inerentes às próprias regressões efetuadas, corresponde à sucessão estratigráfica observada. Na opinião dos autores presentes, tais idades podem ser consideradas válidas, em primeira aproximação, para representar os even- tos deposicionais de cada formação. Cabe assinalar que valores similares (cerca de $620 \mathrm{~m} . \mathrm{a}$.) foram encontrados por A. Thomaz Filho (trabalho em preparação) ao estudar, pelo método $\mathrm{Rb}-\mathrm{Sr}$ em rocha total, o Grupo Bambuí da região de São Francisco, norte de Minas Gerais, e por Bonhomme (1976), nas frações finas (menores que $2 \mu$ ) de leitos argilosos intercalados nos calcários das regiões de Januária e João Pinheiro.

As idades aparentes mais novas obtidas por esse mesmo autor (Bonhomme, 1976), na região de Cedro do Abaeté, referem-se a material argiloso que foi sujeitado a trocas químicas durante diagêneses tardias ou mesmo eventos de alteração hidrotermal/intempérica ocorridos posteriormente. Nestes casos, tal como demonstraram Cordani et al. (1978), as idades aparentes referem-se às épocas de rehomogeinização isotópica que afeta particularmente as frações finas das rochas de modo que os valores próximos de $550 \mathrm{~m}$.a. e de $450 \mathrm{~m}$.a. devem ser interpretados como associados a eventos secundários, posteriores à sedimentação, tal como indica o próprio Bonhomme na referida publicação.

Por outro lado, é interessante confrontar os dados aqui obtidos, especialmente os relativos à Formação Paraopeba (Fig. 4), com os dados paleontológicos existentes, baseados em estudos de estruturas estromatolíticas, e que até certo ponto apresentam-se conflitantes. Com efeito, Cloud e Dardenne (1973) identificaram, em dolomitos da região de Vazante (MG), Conophyton aff. C. Metula Kiriechenko aos quais atribuíram idade Rifeano Médio (950-1 350 m.a.; mais provável em torno de 1000 m.a.). Essa idade difere da obtida por Marchese (1974) com estromatólitos Supergrupo Gimnosolenida ocorrentes em calcários pretos grafitosos da região de Sete Lagoas (MG) considerados como pertencentes ao Rifeano Superior $(650-950 \mathrm{~m}$.a.).

As dúvidas paleontológicas poderiam ser dirimidas se fosse considerada a possibilidade de as rochas, que até o presente são atribuídas à mesma unidade litoestratigráfica (no caso, a Formação Paraopeba), em verdade representarem materiais de pelo menos duas unidades distintas e com idades diferentes. Aos calcários pretos da região de Sete Lagoas, com estromatólitos do Rifeano Superior, pode ser associada uma idade de $640 \pm 15$ m.a. tal como a obtida para a Formação Paraopeba em situação tectônica estável, na região de Itacarambi, e considerada representativa de seu evento deposicional. 
Alternativamente, aos dolomitos das regiôes de Vazante e Paracatu, com estromatólitos do Rifeano Médio, pode ser associada uma idade minima de $680 \pm 10 \mathrm{~m}$.a. que, no entanto, não representa o evento deposicional da unidade mas uma época de remomogeneização posterior associada a importante evento tectônico/metamórfico regional.

$\mathrm{Na}$ opinião dos presentes autores, a unidade estratigráfica que ocorre em Vazante e Paracatu pode ter sido depositada muito antes que a idade aparente indicada $(680$ m.a.) e não deve ser diretamente correlacionada com a Formação Paraopeba, tal como esta foi caracterizada no eixo Januária-Sete Lagoas. Nesta eventualidade, não há discrepâncias em relação à idade indicada pelos estromatólitos e, além disso, o esquema proposto encontra pleno apoio nos trabalhos de síntese apresentados por Campos Neto (1979), nos quais são caracterizadas as relações estratigráficas e estruturais de grande parte do Sistema de dobramentos Brasília, inclusive a região de Paracatu e Vazante.

Em relação ao chumbo das galenas associadas ao Grupo Bambuí, parece que sua evolução isotópica ocorreu em dois estágios, o primeiro deles terminando com a separação do manto e a incorporação à crosta durante eventos associados ao Ciclo Transamazônico. Este fato confirma a influência deste episódio tectonomagmático como época da maior importância em relação à evolução das rochas crustais que constituem o embasamen- to do Grupo Bambuí. O segundo estágio evolutivo, que terminaria com a incorporação do chumbo às galenas, parece estar associado à tectogênese ocorrida em aproximadamente 600 m.a. em um ou mais episódios do Ciclo Brasiliano. Evidentemente, um maior número de dados sobre composição isotópiça do $\mathrm{Pb}$ em galenas se faz necessário para melhor defininir sua gênese.

Agradecimentos Esta publicação resulta do esforço conjunto da Metamig, do Centro de Pesquisas Geocronológicas do IG-USP (CPGeo) e do Instituto de Pesquisas Energéticas e Nucleares (IPEN) de São Paulo. Cabem à Metamig os estudos geológicos e estratigráficos regionais, e a coleta das amostras analisadas; ao CPGeo-USP, as dataçðes pelo método $\mathrm{Rb}-\mathrm{Sr}$; e, ao IPEN, as medidas de composição isotópica de $\mathrm{Pb}$ nas galenas disponíveis. Os autores agradecem a colaboração das várias pessoas e entidades que possibilitaram a presente publicação. De início, à diretoria da Metamig pela autorização em utilizar dados internos da empresa. Aos geólogos A. E. Rabelo, V. F. Veronese e a A. Madalosso, pelo auxílio prestado nas operaçoes de campo. Ao pessoal técnico do CPGeo e do IPEN, pela colaboração prestada no desenvolvimento das análises $\mathrm{Rb}-\mathrm{Sr}$ e de composição isotópica de $\mathrm{Pb}$. Finalmente, ao Dr. J. Richards, da Australian National University, são devidas valiosas informações relativas à metodologia empregada pelo pessoal do IPEN.

\section{BIBLIOGRAFIA}

ALMEIDA, F. F, M. de e HASUI, Y. - 1969 - Geocronologia do CentroOeste Brasileiro. Mineraçao e Metalurgia, Rio de Janeiro, 50 (295): 46, julho.

AMARAL, G. - 1966 - Isótopos de chumbo e gênese das jazidas de Vazante e Itacarambi. Anais do $X X$ Congresso. Sociedade Brasileira de Geologia. Rio de Janeiro, pp. 45.46 .

AMARAL, G, - 1968 - Aplicaçăo do estudo da composiçăo isotópica do chumbo a problemas metalogenéticos: resultados preliminares para galenas de depósitos do Grupo Bambul. Anais do XXII Congresso. Sociedade Brasileira de Geologia. Belo Horizonte, pp. 131-138.

AMARAL, G. E KAWASHITA, K. - 1967 - Determinação da idade do Grupo Bambuí pelo método $\mathrm{Rb} / \mathrm{Sr}$. Anais do XXI Congresso. Sociedade Brasileira de Geologia. Curitiba, pp. 214-217.

BEURLEN, K. - 1956 - Idade da Série Bambui. In: DNPM-DGM. Relatório Anual do Diretor, 1955. Rio de Janeiro, pp. 96-97.

BEURLEN, K. e CASSEDANNE, J. - 1963 - Descoberta de collênia no calcário do Bambuí. Arquivos de Geologia, Recife (4): 1-9

BONHOMME, M. G. - 1976 - Minéralogie des fractions fines et datations Rb-Sr dans le Groupe Bambuí. Revista Brasileira de Geociências 6 (4): 211-222:

CAMPOS NÉTO, $\overline{\mathrm{M}}$. C. - 1979 - Contribuition a l'étude tectonique des Brasilides: stratigraphie et structure du Groupe Canastra et du Supergroupe Săo Francisco a la bordure occidentale du Craton du Săo Francisco (MG-Brésil) - Paris VI - Tese $3{ }^{\circ}$ Ciclo (inédito).

CASSEDANNE, J. P. - 1973 - Paléogéographic et mineralisations de la zone Itacarambi Vazante dans le nord-ouest de l'état de Minas Gerais, Brésil. Mineral. Deposita 8: 101-114.

CASSEDANNE, J. P. e LASSERRE, M. - 1969 - Ettude géologique et analyse isotopique par la méthode au plombe de quelques galènes du Brésil. Bulletin B.R.G.M. Ser, 2 Sec. 4 (1): 71-87.

CLOUD, P. E DARDENNE, M. A. - 1973 - Proterozoic age of the Bambui Group in Brasil. Geological Society of America Bulletin 84 (5): 1673-1676.

COMPSTON, W., CHAPPEL, R. W., ARRIENS, P. A. e VERNON, M. S, 1969 - On the feasibility of NBS 70-A K-Feldspar as a Rb-Sr age reference samples. Geochim. et Cosmoch. Acta 33: 753-757.

COOPER, J. A., REYNOLDS, P. H. e RICHARDS, J. R. - $1969-$ Double spike calibration of the Broken Hill Standard lead. Earth Planet. Sci. Lett. 6: $467-478$.

CORDANI, U. G., KAWASHITA, K. e THOMAZ FILHO, A. - $1978-A p$ plicability of the Rubidium - Strontium method to shales and related rocks. Tulsa/, AAPG./Separata de American Association of Petroleum Geologists. Contributions to the geologic time scale./ Tulsa/, s.d. pp. 93-117 (AAPG, Studies in Geology, 6).
COUTO, J. G. Parenti, ALECRIM, J. D. e PINHEIRO, S. O. - 1978 - Reconhecimento geológico-geoquímico das Formaçðes Três Marias e Pirapora (Grupo Bambui). Anais do $X X X$ Congresso. Sociedade Brasileira de Geologia. Recife, v. S, pp. 2059-2073.

CUMMING, G. L. e RICHARDS, J, R. - 1975 - Ore lead isotope rations in acontinously changing earth. Earth Planet. Sci. Lett. 28: 155-171.

DERBY, Orville Adelbert - 1879 - Contribuiçăo para o estudo da geologia do Vale do Rio Săo Francisco. Archivos do Museu Nacional, Rio de Janeiro, 6: 87-119.

FAURE, G., HURLEY, P. M. e POWELL, J. L. - 1965 - The isotopic com position of strontium in surface water from the North Atlantic Ocean. Geoch. Cosmoch. Acta 29: 209-220.

HURLEY, P. M.; ALMEIDA, F, F. M. de, MELCHER, G, C., CORDANI, U. G., RAND, J., KAWASHITA, K., VANDOROS, P., PINSON, W. H. e FAIRBAIRN, H. W. - 1967 - Test of Continental Drift by comparison of radiometric ages. Science 144: 495-500.

KAWASHITA, K. - 1973 - O método Rb-Sr em rochas sedimentares - Aplicaçăo para as Bacias do Paraná e do Amazonas. Tese de doutoramento, IGUSP (inédito).

KAWASHITA, K., MANTOVANI, M., THOMAZ Fo., A., TORQUATO, J. R. e BERENHOLC, M. - 1974 - Método radiometrico rubidio-estróncio Procedimento das análises no Centro de Pesquisas Geocronológicas da Universidade de São Paulo. 106 p. Manual Interno, IG-USP.

LIAIS, E. - 1872 - Climat, géologie, faune et géographie botanique du Brésil, VIII. Paris, Georges Chamerot.

MARCHESE, H. C. - 1974 - Estromatolites "gymnosolenidos" en el lado Oriental de Minas Gerais. Revista Brasileira de Geociências 4: 257-271.

REYNOLDS Jr, R. C. - 1963 - Matrix corrections in trace element analysis by X-Ray fluorescence: estimation of the mass absortion coefficient by Compston scattering. Am. Min. 48: 1133-1143.

STACEY, J. S., DELEVAUX, M. H. e ULRYCH, T. J. - 1969 - Some triple filament lead isotope ratio measurements and an absolute growth curve for single stage leads. Earth Plonet. Sci. Lett. 6:15-25.

STRELOW, F. W, e VAN TOERIEN, F. $-1966-$ Separation of lead (II) from bismuth (III), mercury (II), gold (III), platinum (VI), paladium (II) and other elements by anian exchange cromatography. Analytical Che mistry 38: $545-548$.

THORPE, R. - 1974 - Lead isotope evidence on the genesis of the silver arsenide vein deposits of the Cobalt and Great Bear Lake area, Canada. Econ. Geol. 69: 777.791.

YORK, D. -1969 - Least square fitting of a straight line with correlated erroes. Earth Planet. Sci. Lett. 5: 320-324.

Recebido em 14 de julho de. 1980 